\title{
"Teaching ophthalmology for undergraduate medical students" 40 years experience in problem based, community oriented institutions
}

\begin{abstract}
The author had 40 years of experience in continuous teaching Ophthalmology in different academic institutions. He was a pioneer in founding the Ophthalmology Department, Faculty of Medicine, Suez Canal University, Ismaillia, Egypt. Putting the plans of studying Ophthalmology in an integrated way with other college specialties in both academic \& clinical departments. He had the chance to work as a visiting professor of ophthalmology in Umm A1-Qura University, Mecca (2000-2002), Aljouf University (2011-2013) and Najran University (2013-2014), KSA. Our successful Ophthalmology plans of education were put and applied in Saudi Institutions as well.
\end{abstract}

\begin{abstract}
Aim: Ophthalmology is an important subject to study in medicine. We thought it is not enough to be given for medical students in few days only. We wish to have a well trained, good efficient competent graduate, aware of the community health problems, able to solve any unexpected medical situation during practice in a well safe organized format. Ophthalmology skill lab and well designed written Ophthalmology problems are given in Problem based learning (PBL) classrooms \& at field education in academic phase. Hospital clinical training including Outpatient Department, video sessions, lectures, seminars with logbook guide line with objective structured clinical examination (OSCE) are used in clinical phase evaluation.
\end{abstract}

Keywords: ophthalmic education, problem based learning, community oriented institute, objective structured clinical examination
Volume 7 Issue 3 - 2017

\author{
Osama Elbassiouny \\ Ophthalmology Department, Suez Canal University, Egypt
}

Correspondence: Osama Elbassiouny, Professor \& Founding Director of Ophthalmology Department, Senior Consultant Ophthalmic Surgeon, Suez Canal University Hospital, FOM, SCU, Ismaillia, Egypt, Email osama.elbassiouny@med.suez.edu.eg

Received: July 30, 2017 | Published: August 28, 2017
Abbreviations: PBL, problem based learning; OSCE, objective structured clinical examination; EBM, evidence-based medicine; NARS, national academic reference standards; NAQAAE, national authority of quality assurance and accreditation in education; OPD, ophthalmic outpatient department; LCE, long case exam

\section{Our system}

Faculty of Medicine, Suez Canal University started in Ismaillia, Egypt, 1978. ${ }^{1}$ Education system is adopting an innovative curriculum. Evidence-based medicine (EBM) has been integrated into problem based learning (PBL) sessions as a responsive innovative paradigm for the practice and teaching of clinical medicine i.e. problem based, community oriented, student-centered methods of education. ${ }^{2}$ Other Egyptian medical schools are generally adopting the conventional teacher-centered and subject-based curricula. Some starting to introduce changes in their curricula in order to fulfil the National Academic Reference Standards (NARS), published in 2008 by the National Authority of Quality Assurance and Accreditation in Education (NAQAAE). ${ }^{3,4}$ Concerning Ophthalmology, no ready formulas were present to apply. We try to put plans for undergraduate medical students to learn medicine in an integrated way of thinking. ${ }^{5}$ All founding faculty members had several workshops to became oriented and build up unique educational system to the newly born college of medicine in the Middle East \& Africa. Study Medicine is six years. The first three years is academic phase and the last three years are the clinical phase. Ophthalmic Skill lab is an essential item for practical training to all medical students in the academic phase.

First year medical students were given a simple guide line about optics, glasses, mirrors and prisms for presbyopia changes that happen due to aging process. They were also trained and evaluated for visual acuity testing. Second year, were given skill training for external eye examination using a source of light and magnification (loop) if possible. Third year students, are given fundus examination on eye modules. Practical session is given for them to try examining each other. A check list is available in the skill lab as a guide line for students for skill steps and they are evaluated by items present in each skill test. No student is allowed to be promoted without satisfactory performance of each nominated test. Written Ophthalmic problems (neuro-ophthalmology) for third year students is given to them in PBL classes (Figures 1\&2). In order to prepare the students for acquiring necessary information about the human body (anatomy \& physiology), general skill lab (Figure 3 ) is essentially required for basic academic education. Having a decent Ophthalmic Skill lab (Figure 4) is the key for basic undergraduate Ophthalmic teaching. We give our students a clinical training in rural \& urban primary health care units from early years of academic phase of education.

Clinical phase need hospital training. We started teaching \& practical training for students by using general hospital in our locality in Suez Canal Zone (Ismaillia, Portsaid and Suez). Faculty staff will be facilitated to join students at their nominated training sites. Figure 5 shows clinical round in Alsidairy General Hospital in Aljouf, KSA, to teach the students how to use ophthalmic unit. Ophthalmology course usually starts smoothly, since students are already knew anatomy \& physiology of the eye and its examination in the academic year period. Now, We are working in SCU hospital since 1993 (Figures 1\&6). Clinical Ophthalmology course is given during six weeks of fifth year college student. In the Ophthalmic Outpatient Department (OPD), we have several examinations units. Each student is guided by portfolio 
booklet (Table 1) given to them at beginning of clinical period. This portfolio provides a source of evidence for assessment committee that each student attained the desired level of competency required to gain the award for all clinical, academic, other experiences and skills attained during course training. A group of students start early morning in OPD to see closely how to take ophthalmic history and how to do eye examinations \& management. The other group starts by video session. Exchange shift rotation is planned between both groups. All groups will have a lecturer (form one of Ophthalmology staff member) in the afternoon period for two hours. Wednesday each week is given for OSCE and Multiple choice training. Evaluations includes: End course evaluations (short clinical cases, OSCE and portfolio clinical discussion) and final year written \& multiple choice exams. New Specialized University Hospital is now available in Ismaillia to upgrade our health delivery system in our locality.

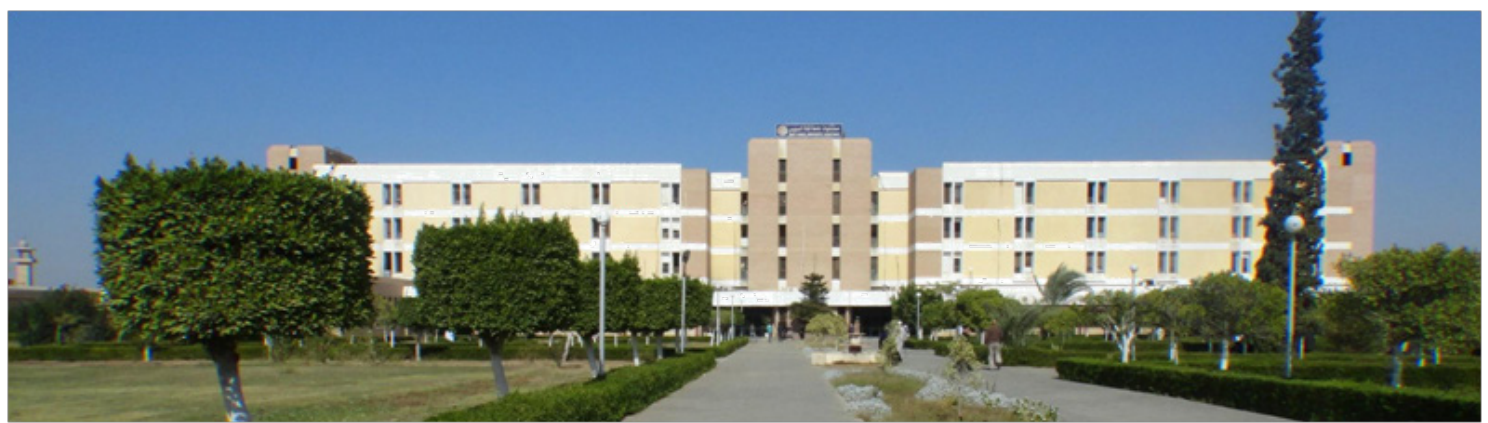

Figure I Suez Canal University Hospitals Photograph.

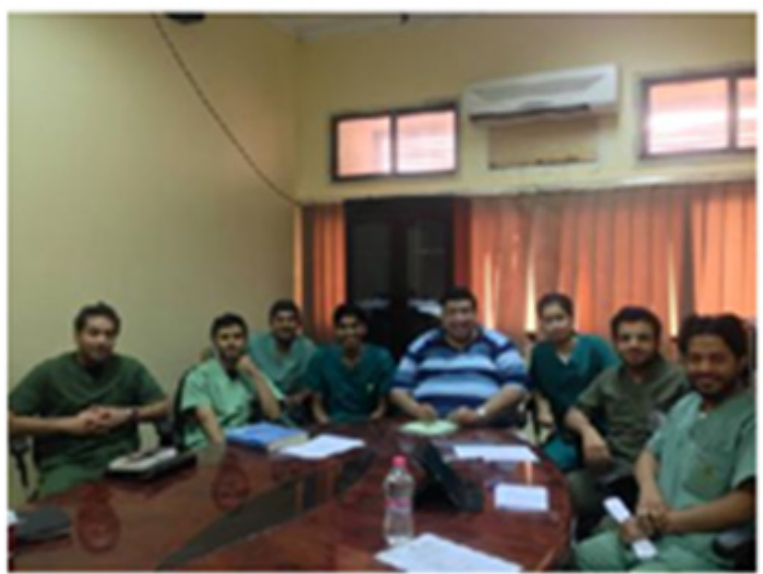

Figure 2 PBL Class in Aljouf.

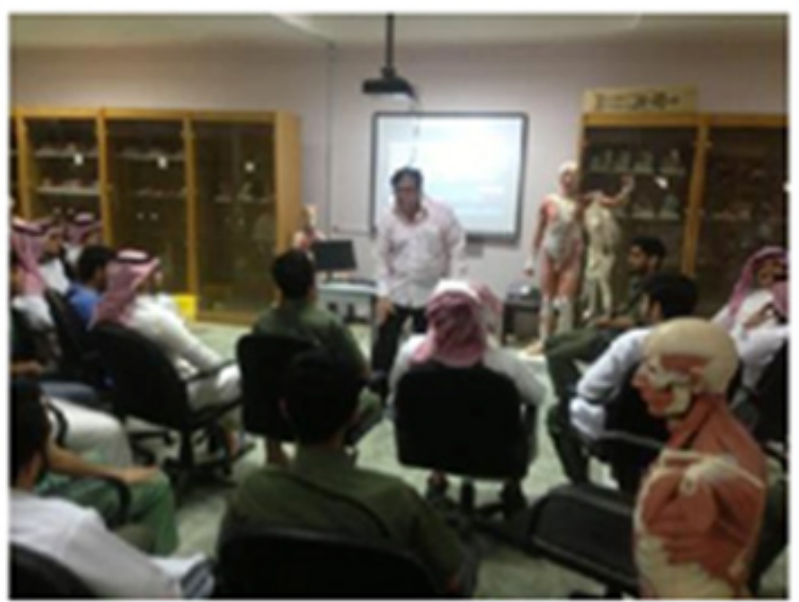

Figure 3 Skill lab in Aljouf.

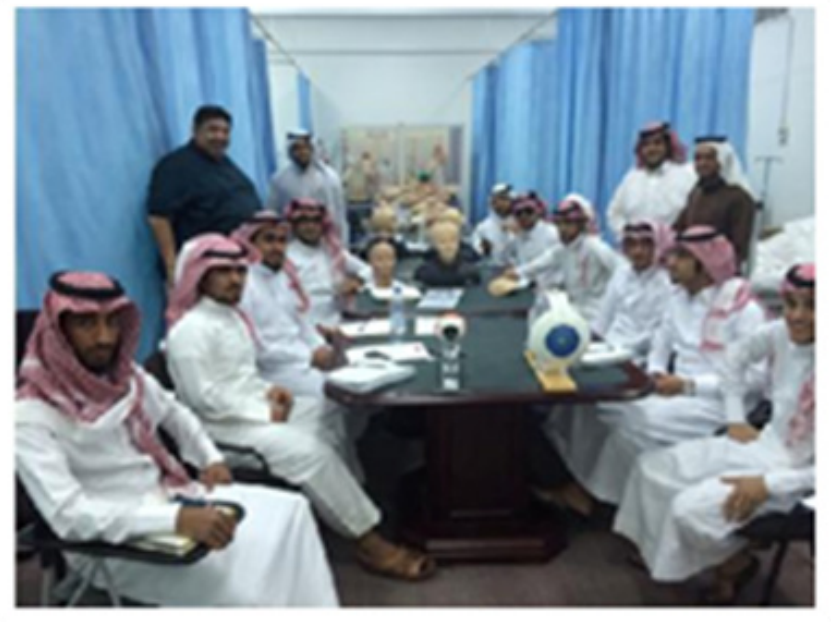

Figure 4 Ophthalmic skill lab Najran.

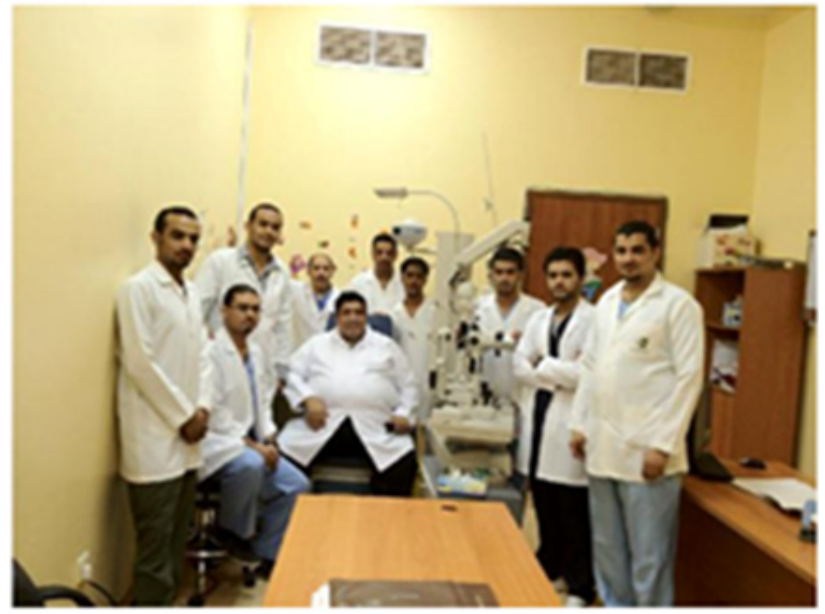

Figure 5 Group Clinical training in Aljouf. 
Table I Scoring Criteria of Ophthalmology Portfolio (Score/ total: 100\%).N.B. Any student scores should not be less than $60 \%$

\begin{tabular}{lll}
\hline I. & Psychomotor skills & $40 \%$ \\
2. & Spot Diagnosis Cases & $40 \%$ \\
3. & Professionalism & $10 \%$ \\
4. & Attendance to outpatient Clinics & $10 \%$ \\
5. Personal learning plan & Done/ Not done \\
6. & Reflection & Done/ Not done \\
\hline
\end{tabular}

\section{Results}

We have now graduated several generations of our graduates since 1987. Some of them became now a professor and leaders in different Faculty Departments (including Ophthalmology). Since our system of education concerned about Community problems, our graduates are more competent and efficient in solving these problems. Since the rule of education is student centered, the graduate is more competent as an active health team worker. Those graduates who specialized in Ophthalmology are more successful in patient management \& doing postgraduate searches in smooth way than other graduates from traditional ophthalmic education.

\section{Discussion}

FOMSCU has a reputable history in the field of medical education since 1977. It has provided a repository for resources such as consultants, innovative curricula, data sets, syllabi and instructional material to a number of areas in Egypt and the Eastern Mediterranean Region. In 1987, was declared as WHO Collaborating Center in Medical Education and continued to be so till now. In 2010, it was declared by the Egyptian National Authority for Quality Assurance and Accreditation of Education as the first accredited higher education institution in Egypt. We started our education with no University Hospital. We decided to use all the available community facilities in order to employ our optimistic educational system in rural \& urban primary health care unites as well as general hospitals along Suez Canal Zone. The long case exam (LCE) has been used for long time to assess medical students' clinical competence throughout the world. However, its major flaw related to reliability issues made it unwise to use as the sole basis for making decisions of consequence. The major reliability problems of LCE are the case-specificity (difference in cases), differences between examiners and variability in the aspects that surround the encounter. ${ }^{6}$ We use objective structured clinical examination (OSCE) as a resource-intensive assessment method instead of LCE.?

We followed Maastricht University (UM) which is known for its Problem-Based Learning system and international orientation. ${ }^{8}$ They are focused on helping students to get the best out of themselves and preparing them as for future career. In PBL system the Learner centered rather than Teacher centered. The main task of Faculty tutor (any Faculty specialty) is to promote both the learning process and group dynamics. In PBL process includes: 1. The Problem. Describes a real world phenomenon; 2. Tutorial or Small group discussion; 3. Self directed study; 4. Exchange of information. Small classroom student discussion enhance student character to upgrade themselves and to have practical training to work in a group. Each student has a chance to be a leader for his group. At the end of study session, assessment of reflection on tutor, student \& group performance are evaluated. Our graduate is more competent to work in a team and trained to be efficient leaders for a medical team especially if they nominated in rural areas.

My experience in the Kingdom of Saudi Arabia KSA is unique. In Mecca, Aljouf and Najran, I was nominated to have the job because of my educational experiences in Suez Canal University. No University Hospital was found at the time of my existence in these places. In each place, I immediately started Ophthalmology skill lab and check list for evaluation. All students have to be trained and succeed before going to local general hospital available in these places. Started to write problems for students to discuss and study. Attended seminars for student's group discussion. Worked as class \& field tutor. Teaching Ophthalmology in clinical phase. I gave each student objective of the course. Required hospital criteria for learning. Since the student's number was limited, every student chooses an ophthalmic topic at the beginning of the course and writes an essay about it. At the end of the course, each student presents his topic to his colleague for discussion and evaluation. I put my course in the University web site. Each student can use it with his student ID. Weekly quiz were put for them to keep connect with the course tutor. OSCE is the standard system for evaluation to all medical students in clinical phase education. ${ }^{9}$ Questionnaire was used to monitor student satisfaction and their recommendations to be taken in consideration for future groups.

In Ismailia, we adopted a problem based, community oriented curriculum, emphasizing self learning, continues updating, mastering of skills, community links and moral integrity and sound ethical attitudes. We are always eager to update our curriculum, our teaching strategies, our evaluation approaches and all other aspects of academic Life. FOM/SCU members have also offered training and consultations to numerous medical schools in other countries, including Syria, Libya, Yemen, Sudan, Somalia, and Ethiopia.

\section{Acknowledgements}

I would like to thank my Ophthalmology working team that helped me to accomplish continuous success in service and education (Figure 6). We cannot forget our late Dean Zohir Nooman and professor Esmat Ezzat that put the concept of our institute and change the concept to reality.

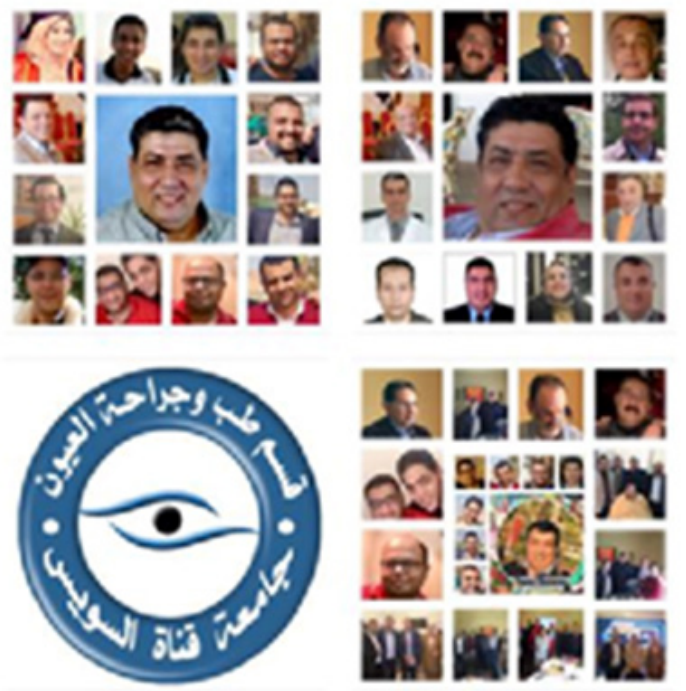

Figure 6 Ophthalmic team in SCU. 


\section{Conflicts of interest}

There are no conflicts of interest.

\section{Funding}

None.

\section{References}

1. Innovation in medical education: an evaluation of its present status. In Nooman ZM, editor. Springer Series on Medical Education, New York, USA: Springer; 1990.

2. Hosny S, Ghaly MS. Teaching evidence-based medicine using a problem-oriented approach. Med Teach. 2014;36(Supp1):S62-S68.

3. Hosny S, El Wazir Y, El Kalioby M, et al. Role of Suez Canal University, Faculty of Medicine in Egyptian Medical Education Reform. Health Professions Education. 2016;2:44-50.
4. NAQAAE. National Academic Reference Standards. Medicine. 2009.

5. Snyman WD, Kroon J. Vertical and horizontal integration of knowledge and skills - a working model. Eur J Dent Educ. 2005;9(1):26-31.

6. Norcini J, Waas V, Jones R, et al. The validity of long cases. Med Educ. 2002;35:735-736.

7. Abdelaziz A, Hany M, Atwa H, et al. Development, implementation, and evaluation of an integrated multidisciplinary Objective Structured Clinical Examination (OSCE) in primary health care settings within limited resources. Med Teach. 2016;38(3):272-279.

8. Hamad B. What is community-based education? evolution, definition and rationale. In: Schmidt HG, Felletti G, editor. Handbook of Communitybased Education: Theory and Practices. Network, Netherlands: Maastricht; 2000.

9. McLaughlin K, Gregor L, Jones A, et al. Can standardized patients replace physicians as OSCE examiners?. BMC Med Educ. 2006;6:12. 